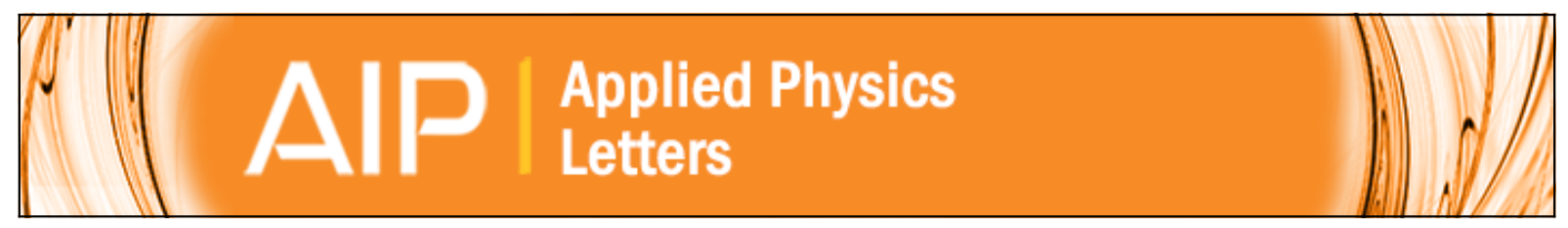

\title{
Indentation-induced damage in GaN epilayers
}

J. E. Bradby, S. O. Kucheyev, J. S. Williams, J. Wong-Leung, M. V. Swain, P. Munroe, G. Li, and M. R. Phillips

Citation: Applied Physics Letters 80, 383 (2002); doi: 10.1063/1.1436280

View online: http://dx.doi.org/10.1063/1.1436280

View Table of Contents: http://scitation.aip.org/content/aip/journal/apl/80/3?ver=pdfcov

Published by the AIP Publishing

\section{Articles you may be interested in}

Effect of indium surfactant on stress relaxation by $\mathrm{V}$-defect formation in $\mathrm{GaN}$ epilayers grown by metalorganic chemical vapor deposition

J. Appl. Phys. 108, 093511 (2010); 10.1063/1.3487955

Stress dependence of the near-band-gap cathodoluminescence spectrum of GaN determined by spatially resolved indentation method

J. Appl. Phys. 100, 083515 (2006); 10.1063/1.2360152

Deformation behavior of ion-beam-modified GaN

Appl. Phys. Lett. 78, 156 (2001); 10.1063/1.1335552

Nanoindentation of epitaxial GaN films

Appl. Phys. Lett. 77, 3373 (2000); 10.1063/1.1328047

Elastic and plastic properties of GaN determined by nano-indentation of bulk crystal Appl. Phys. Lett. 75, 2070 (1999); 10.1063/1.124919

\section{AIP $\left.\right|_{\text {APL Photonics }}$}

APL Photonics is pleased to announce Benjamin Eggleton as its Editor-in-Chief

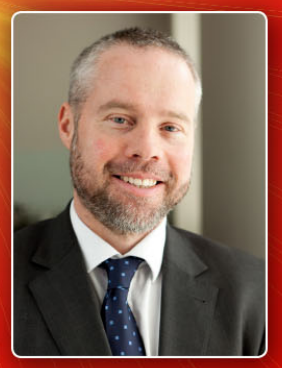




\title{
Indentation-induced damage in GaN epilayers
}

\author{
J. E. Bradby, ${ }^{\text {a) }}$ S. O. Kucheyev, J. S. Williams, and J. Wong-Leung
}

Department of Electronic Materials Engineering, Research School of Physical Sciences and Engineering, The Australian National University, Canberra, ACT 0200, Australia

M. V. Swain

Biomaterials Science Research Unit, Department of Mechanical and Mechatronic Engineering and Faculty of Dentistry, The University of Sydney, Eveleigh, NSW 1430, Australia

P. Munroe

Electron Microscope Unit, University of New South Wales, Sydney, NSW 2052, Australia

G. Li

Ledex Corporation, No. 9, Ta-Yio First St., Ta-Fa Industrial District, Kaohsiung County, Taiwan, Republic of China

M. R. Phillips

Microstructural Analysis Unit, University of Technology, Sydney, Broadway, NSW 2007, Australia

(Received 26 July 2001; accepted for publication 9 November 2001)

The mechanical deformation of wurtzite $\mathrm{GaN}$ epilayers grown on sapphire substrates is studied by spherical indentation, cross-sectional transmission electron microscopy (XTEM), and scanning cathodoluminescence (CL) monochromatic imaging. CL imaging of indents which exhibit plastic deformation (based on indentation data) shows an observable "footprint" of deformation-produced defects that result in a strong reduction in the intensity of CL emission. Multiple discontinuities are observed during loading when the maximum load is above the elastic-plastic threshold, and such a behavior can be correlated with multiple slip bands revealed by XTEM. No evidence of pressure-induced phase transformations is found from within the mechanically damaged regions using selected-area diffraction patterns. The main deformation mechanism appears to be the nucleation of slip on the basal planes, with dislocations being nucleated on additional planes on further loading. XTEM reveals no cracking or delamination in any of the samples studied for loads of up to $250 \mathrm{mN}$. (C) 2002 American Institute of Physics. [DOI: 10.1063/1.1436280]

Gallium nitride is the focus of intensive research due to its applications for the fabrication of (opto)electronic devices. ${ }^{1}$ The properties and deformation mechanisms of this material are therefore of significant technological importance, with contact-induced damage, cracking, and epilayer delamination being of particular interest. A number of groups have studied the deformation behavior of GaN using indentation for inducing mechanical damage ${ }^{2-7}$ and/or for measuring the material properties. ${ }^{8-13}$ On indentation loading of $\mathrm{GaN}$, a discontinuity in the load-penetration curve (so called "pop in") has been reported in some studies ${ }^{9,13}$ but not in others. ${ }^{10}$ In the latter case, Nowak et al. ${ }^{10}$ have attributed the reported discontinuities to the influence of the underlying sapphire substrate.

Discontinuities in the indentation load-penetration curves have also been reported for a number of other brittle semiconductor materials (such as $\mathrm{Si}, \mathrm{Ge}$, InP, and GaAs). These discontinuities are widely recognized as an important indicator of physical deformation processes such as the initiation of dislocations or phase transformations. ${ }^{14-16}$ In the case of $\mathrm{GaN}$, atomic force microscopy (AFM) of indents has revealed slip traces within the contact diameter of the indenter, which suggests that slip is the mechanism of plastic deformation in this material. ${ }^{13}$ However, a recent study by

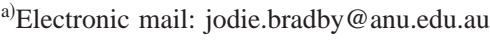

Weyher et al. ${ }^{6}$ have reported the formation of some polycrystalline material in the highly deformed residual indent impression in $\mathrm{GaN}$. These authors have speculated that this may be a result of pressure-induced phase transformations. ${ }^{6}$ It is clear that low-load mechanical deformation of $\mathrm{GaN}$ by indentation has not been studied in sufficient detail in order to determine the major modes of plastic deformation. In particular, no cross-sectional transmission electron microscopy (XTEM) studies of indents in GaN have been reported despite the fact that XTEM has proven to be a powerful technique to study indentation-produced structural changes in other brittle materials. Hence, we report here on a XTEM study of indentation-deformed $\mathrm{GaN}$ to probe microstructural changes.

In this letter, we investigate the deformation of $\sim 2 \mu \mathrm{m}$ thick wurtzite epilayers of GaN grown on sapphire substrates by metalorganic chemical vapor deposition in a rotating disk reactor at Ledex Corp. A series of indentations was made at loads of up to $250 \mathrm{mN}$ with an Ultra Micro Indentation System 2000 (UMIS). A spherical indenter of an $\sim 4.2 \mu \mathrm{m}$ radius was used throughout this study. Both the UMIS and indenter tip were calibrated using fused silica. All indents were made using the continuous load-unload cycle at room temperature and atmospheric pressure. The indented material was analyzed using both XTEM and scanning cathodoluminescence (CL) monochromatic imaging. The CL study was performed at room temperature using an Oxford Instruments 


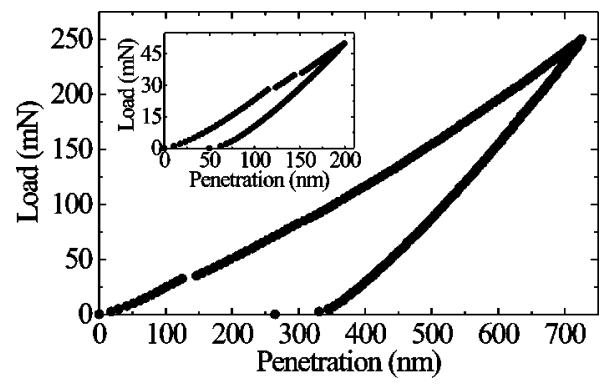

FIG. 1. Typical load-penetration curve for a maximum load of $250 \mathrm{mN}$ showing a pop-in event. Inset: Load-penetration curve for a maximum load of $50 \mathrm{mN}$ showing multiple pop-in events at 28 and $34 \mathrm{mN}$.

Mono CL2 system, installed on a JEOL 35C scanning electron microscope (SEM).

Samples for XTEM were prepared using an FEI $\times$ P200 focused ion beam (FIB) system with $30 \mathrm{keV}$ Ga ions. To protect the surface during the ion milling process, an $\sim 2$ $\mu \mathrm{m}$-thick layer of Pt was deposited over the surface using the FIB instrument. To avoid ion-beam-induced damage, ion current was kept as low as practicable $(<70 \mathrm{pA}$ when imaging sample) to minimize the dose the samples received both before and after Pt was deposited. The transmission electron microscope used in this study was a Philips CM 300 operated at an accelerating voltage of $300 \mathrm{kV}$.

Figure 1 shows a typical load-penetration curve from $\mathrm{GaN}$ loaded to a maximum of $250 \mathrm{mN}$. At this load, the indenter penetrates $\sim 730 \mathrm{~nm}$ into the material. A single discontinuity is clearly observed on loading at $\sim 35 \mathrm{mN}$. The inset in Fig. 1 shows a load-penetration curve taken with a maximum load of $50 \mathrm{mN}$. In this case of lower load indentation, the maximum indenter penetration is $\sim 200 \mathrm{~nm}$, which is approximately a tenth of the GaN epilayer thickness. This curve shows two pop-in events at $\sim 28$ and $\sim 34 \mathrm{mN}$. Multiple pop ins were found in a number of load-penetration curves collected from GaN. The critical load and the length of indenter excursion during pop-in events were found to vary markedly even between indents made on the same sample under identical loading conditions. However, these effects were found to have a negligible influence on the final penetration depth of the indenter.

After indentation, the residual indent impressions were imaged using CL. A series of CL images of near-gap emission from $\mathrm{GaN}$ indented to maximum loads of $25 \mathrm{mN}, 50$ $\mathrm{mN}$, and $200 \mathrm{mN}$ is shown in Figs. 2(a), 2(b), and 2(c), respectively. All the indents shown in Fig. 2 were loaded above the pop-in threshold (based on the indentation data). In these CL images, deformation-produced defects are
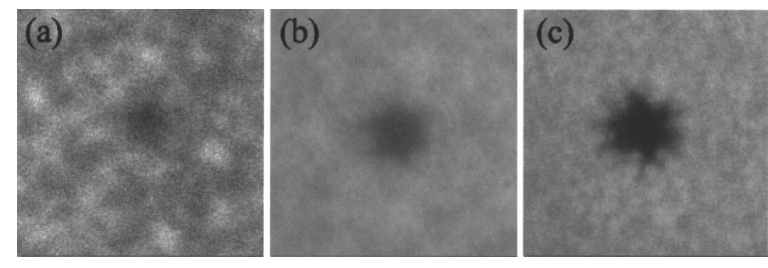

FIG. 2. Room-temperature monochromatic CL images of spherical indents in GaN. The maximum loads and horizontal field widths are (a) $25 \mathrm{mN}$ and $\sim 15 \mu \mathrm{m}$, (b) $50 \mathrm{mN}$ and $\sim 15 \mu \mathrm{m}$, and (c) $200 \mathrm{mN}$ and $\sim 30 \mu \mathrm{m}$. CL imaging conditions: electron beam energy $=20 \mathrm{keV}, \mathrm{CL}$ wavelength $=366 \mathrm{~nm}$, and CL bandpass $=2.5 \mathrm{~nm}$.

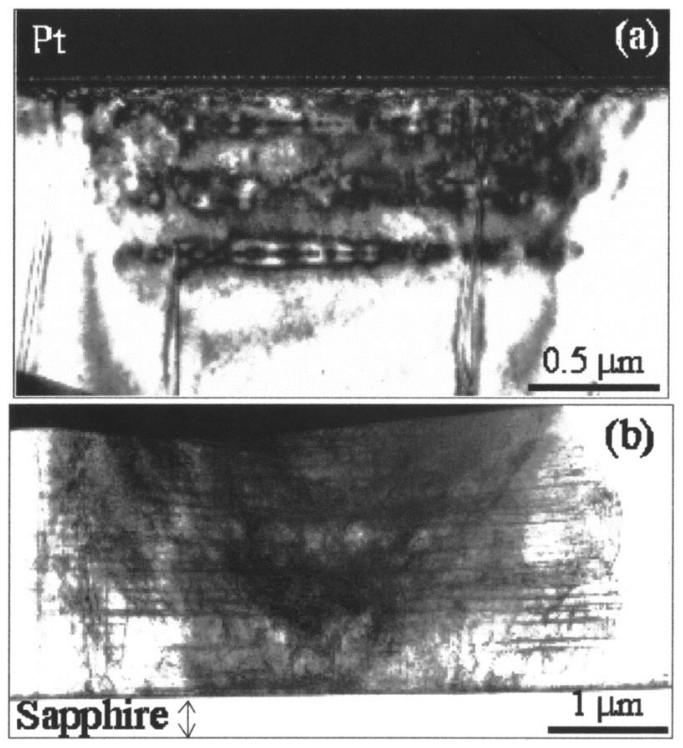

FIG. 3. Bright-field XTEM images of spherical indents in $\mathrm{GaN}$ at maximum loads of (a) $50 \mathrm{mN}$ and (b) $250 \mathrm{mN}$.

clearly visible as dark regions where the intensity of the near-gap CL emission from GaN is dramatically suppressed by indentation-induced defects. Indentation-produced dislocations act as a very efficient nonradiative recombination centers in $\mathrm{GaN}$, resulting in a severe suppression of the intensity of the near-gap emission. ${ }^{2,13}$ Figure 2 shows the evolution of the CL "footprint" of such defects with increasing load. The sizes of dark regions in CL are $\sim 3 \mu \mathrm{m}, 5 \mu \mathrm{m}$, and $11 \mu \mathrm{m}$ for $25 \mathrm{mN}, 50 \mathrm{mN}$, and $200 \mathrm{mN}$ indents, respectively. Although Star-of-David-like rosettes have previously been reported around large-load indents, ${ }^{2,13}$ such details could not be clearly resolved for samples indented to lower loads in this study. However, some crystallographically aligned defects can be seen in the images shown in Fig. 2, suggesting that low-load deformation may involve the punching out of dislocations, similar to the high-load case.

Interestingly, CL imaging of GaN indented below the critical pop-in load revealed no detectable reduction in the intensity of CL emission. Indeed, at low maximum loads such as $25 \mathrm{mN}$, where only a small percentage of indents plastically deform, CL imaging was able to distinguish between indents that had undergone some degree of plastic deformation (after pop-in) and indents that were purely in the elastic regime (before pop-in). This was confirmed by an analysis of indentation data for each individual indent. Thus, an observable CL footprint is only detected after the pop-in event. This is convincing evidence that the pop-in event involves the nucleation of slip as the deformation mode.

The microstructures beneath the surface of the indents were examined more directly using XTEM. Bright-field XTEM images of indents in $\mathrm{GaN}$ for maximum loads of 50 $\mathrm{mN}$ and $250 \mathrm{mN}$ are shown in Figs. 3(a) and 3(b), respectively. Both images show threading dislocations running vertically throughout the GaN layer. These as-grown dislocations are characteristic for GaN epilayers. ${ }^{17}$ The image of the $50 \mathrm{mN}$ indent [Fig. 3(a)] shows slip bands aligned parallel to the sample surface along the basal planes. These slip traces extend $\sim 680 \mathrm{~nm}$ down into the GaN epilayer, which is ap- 
proximately three times the maximum indenter penetration depth for this load but merely a third of the thickness of the epilayer. This strongly suggests that, consistent with previous reports, the substrate does not influence the deformation behavior of $\mathrm{GaN}$ at this penetration depth. This result is consistent with a commonly used rule of thumb which states that, when indenting thin films, substrate-independent data can be obtained if the indentation depth is less than one-tenth of the film thickness. ${ }^{18}$

It is interesting to note the three discrete bands of dislocation in Fig. 3(a). This is suggestive of a "slip-stick" behavior, whereby dislocations are pinned by existing defects. Furthermore, this behavior may explain the multiple pop-in event. Indeed, slip may be temporarily impeded (at existing defects) before additional nucleation can proceed as loading increases.

The higher load indent $(250 \mathrm{mN}) /$ shown in Fig. 3(b) reveals a dense array of dislocations extending throughout the entire $\sim 2 \mu \mathrm{m}$ thick $\mathrm{GaN}$ epilayer. Interestingly, no indentation-induced dislocations were found in the sapphire substrate. In addition to slip along the basal plane of $\mathrm{GaN}$, there appear to be dislocations orientated at $60^{\circ}$ to the sample surface. However, the favored slip plane of the hexagonal structure is (0001) (basal plane). The identification of the inclined dislocations planes by detailed tilting experiments is difficult at this load due to the dense array of indentation-produced dislocations. Determination of the Burgers vectors of deformation-produced dislocations in our samples was not possible due to the geometry limitations of the FIB samples.

A selected-area diffraction pattern analysis of mechanically deformed regions revealed no evidence of extra phases in any of the samples studied. This is a compelling argument that no pressure-induced phase transformations take place in $\mathrm{GaN}$ indented at loads up to $250 \mathrm{mN}$ with an $\sim 4.2 \mu \mathrm{m}$ radius spherical indenter. Phase transformations in $\mathrm{GaN}$ have been proposed as a mechanical deformation mechanism by Weyher et al., ${ }^{6}$ who detected a polycrystalline material after Vickers indentation at very high loads of $2 \mathrm{~N}$. Hence, it may be speculated that severe loading conditions, such as used by Weyher et al., ${ }^{6}$ may be needed to induce a phase transformation in GaN.

It is apparent from the above experimental data that there is no substrate influence to loads roughly double those at which the the pop-in event is observed, in contrast to the suggestion by Nowak et al. ${ }^{10}$ For example, pop-in events are clearly seen in the $50 \mathrm{mN}$ indentation data (see the inset in Fig. 1), while the XTEM image for this load shows no evidence of dislocations extending to the GaN/sapphire interface. Even at higher loads of $250 \mathrm{mN}$, where the substrate will clearly influence the deformation processes, no indentation-induced dislocations were found in the substrate in any of the samples studied. Furthermore, no indentationinduced surface cracking has been previously observed by
AFM or SEM in hexagonal GaN. ${ }^{7,13}$ However, film delamination and subsurface cracking were not able to be excluded as a deformation mechanism by previous studies. The present investigation reveals no cracking or delamination for loads up to $250 \mathrm{mN}$ (the maximum load used) and resolves these uncertainties from all previous studies. The only deformation mechanism identified under the medium load conditions used in this study is slip by punching out of dislocations.

In conclusion, this study has enabled the evolution of deformation processes in $\mathrm{GaN}$ by indentation loading to be clearly observed. Slip, by punching out of dislocation bands parallel to the basal plane, is the main mode of plastic deformation. At higher loads, dislocations at $\sim 60^{\circ}$ to the basal planes have been found. No phase transformations, cracking, or delamination of the film was observed under the medium loading conditions of this study. Indeed, the pop-in events during loading can be correlated with indentation-induced dislocations imaged by both CL and XTEM. In particular, multiple pop-in events may originate from multiple slip bands observed by XTEM. Finally, it is interesting to note that CL imaging of indents appears to be a sensitive measure of the onset of slip since CL contrast of indents correlates well with the observation of pop-in events.

${ }^{1}$ See, for example, a review by S. J. Pearton, J. C. Zolper, R. J. Shul, and F. Ren, J. Appl. Phys. 86, 1 (1999).

${ }^{2}$ M. H. Zaldivar, P. Fernándes, and J. Piqueras, Semicond. Sci. Technol. 13, 900 (1998).

${ }^{3}$ M. H. Hong, A. V. Samant, V. Orlov, B. Farber, C. Kisielowski, and P. Pirouz, Mater. Res. Soc. Symp. Proc. 572, 369 (1999).

${ }^{4}$ M. H. Hong, P. Pirouz, P. M. Tavernier, and D. R. Clarke, Mater. Res. Soc. Symp. Proc. 622, T6.18 (2000).

${ }^{5}$ J. L. Weyher, P. D. Brown, J. L. Rouviere, T. Wosinski, A. R. A. Zauner, and I. Grzegory, J. Cryst. Growth 210, 151 (2000).

${ }^{6}$ J. L. Weyher, M. Albrecht, T. Wosinski, G. Nowak, H. P. Strunk, and S. Porowski, Mater. Sci. Eng., B 80, 318 (2001).

${ }^{7}$ P. Kavouras, P. Komninou, M. Katsikini, V. Papaioannou, J. Antonopoulos, and T. Karakostas, J. Phys.: Condens. Matter 12, 10241 (2000).

${ }^{8}$ M. D. Drory, J. W. Ager III, T. Suski, I. Grzegory, and S. Porowski, Appl. Phys. Lett. 69, 4044 (1996).

${ }^{9}$ G. Yu, H. Ishikawa, T. Egawa, T. Soga, J. Watanabe, T. Jimbo, and M. Umeno, J. Cryst. Growth 189, 701 (1998).

${ }^{10}$ R. Nowak, M. Pessa, M. Suganuma, M. Leszczynski, I. Grzegory, S. Porowski, and F. Yoshida, Appl. Phys. Lett. 75, 2070 (1999).

${ }^{11}$ I. Yonenaga, T. Hoshi, and A. Usui, Mater. Res. Soc. Symp. Proc. 595, W3.90.1 (1999).

${ }^{12}$ D. Cáceres, I. Vergara, R. González, E. Monroy, F. Calle, E. Muñoz, and F. Omnés, J. Appl. Phys. 86, 6773 (1999).

${ }^{13}$ S. O. Kucheyev, J. E. Bradby, J. S. Williams, C. Jagadish, M. Toth, M. R. Phillips, and M. V. Swain, Appl. Phys. Lett. 77, 3373 (2000).

${ }^{14}$ E. R. Weppelmann, J. S. Field, and M. V. Swain, J. Mater. Res. 8, 830 (1993).

${ }^{15}$ T. F. Page, L. Riester, and S. V. Hainsworth, Mater. Res. Soc. Symp. Proc. 522, 113 (1998).

${ }^{16}$ J. E. Bradby, J. S. Williams, J. Wong-Leung, M. V. Swain, and P. Munroe, Appl. Phys. Lett. 78, 3253 (2001).

${ }^{17}$ See, for example, X. J. Ning, F. R. Chein, P. Pirouz, J. W. Yang, and M. Asif Khan, J. Mater. Res. 11, 580 (1996).

${ }^{18}$ See, for example, T. Y. Tsui and G. M. Pharr, J. Mater. Res. 14, 292 (1999). 